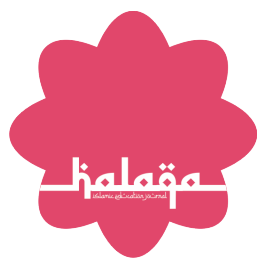

OPEN ACCESS ISSN 2503-5045 (online) ISSN 1412-9302 (print)

Edited by: Eni Fariyatul Fahyuni

Reviewed by: Khozin ${ }^{*}$ Correspondence: Dessy Fitria desyfitria@gmail.com

Received: 3 Oktober 2020 Accepted: 15 Oktober 2020 Published: 25 Oktober 2020

Citation:

Fitria D, Saifudin S and Zaman B (2020) The Effect of E-Learning on

Learning Motivation in Islamic Religious Education Subjects. Halaqa. 4:2.

doi: 10.21070/halaqa.v4i2.984

\section{The Effect of E-Learning on Learning Motivation in Islamic Religious Education Subjects}

\section{Pengaruh E-Learning Terhadap Motivasi Belajar Mata Kuliah Pendidikan Agama Islam}

\author{
Dessy Fitria*, Saifudin Saifudin, Badrus Zaman \\ Institut Agama Islam Negeri Salatiga atau IAIN Salatiga, Indonesia
}

This study aims to determine the effect of the use of E-learning learning on learning motivation of PTKIN students from various provinces in Indonesia, through testing differences in learning motivation between students who use E-learning and students who do not use E-learning. The method used in this study uses a quantitative method. The population and sample used in this study were students from various provinces in Indonesia with 103 respondents, data collection was done using online questionnaires and assisted by using the SPSS application to test the significance of the influence of independent variables (use of e-learning) on the dependent variable (learning motivation college student). SPSS test results show that the use of E-learning has a positive and significant effect on the learning motivation of millennial students today. Can be known from the results of this study showed an F-test of 89,543 with a significant value of 0,000. The use of E-learning in learning has a considerable influence in the success of millennial students learning in Indonesia because it can be seen that the millennial generation has started to get bored and bored with face-to-face learning without pauses. The use of E-learning has an effect on student motivation because in this system students are required to be more creative and independent in seeking information from various sources anytime and anywhere. Thus, learning using E-learning can be applied and maximized because it is proven to increase PTKIN's millennial students' learning motivation from various provinces in Indonesia.

\section{Keywords: E-learning, Motivasi Belajar, Mahasiswa PTKIN}

Penelitian ini bertujuan untuk mengetahui pengaruh penggunaan pembelajaran Elearning terhadap motivasi belajar mahasiswa PTKIN dari berbagai provinsi di Indonesia, melalui pengujian perbedaan motivasi belajar antara mahasiswa yang menggunakan E-learning dengan mahasiswa yang tidak menggunakan E-learning. Metode yang digunakan dalam penelitian ini menggunakan metode kuantitatif. Populasi dan Sampel yang digunakan dalam penelitian ini adalah Mahasiswa dari berbagai provinsi dilndonesia dengan 103 responden, pengumpulan data dilakukan dengan menggunakan kuesioner secara online dan dibantu dengan menggunakan aplikasi SPSS untuk menguji signifikansi pengaruh variabel independen (penggunaan e-learning) pada variabel 
dependen (motivasi belajar mahasiswa). Hasil uji SPSS menunjukkan bahwa penggunaan E-learning memiliki pengaruh positif dan signifikan terhadap motivasi belajar mahasiswa milenial saat ini.Dapat diketahui dari hasil penelitian ini menunjukan F-test 89,543 dengan nilai signifikan 0,000.Penggunaan E-learning dalam pembelajaran memiliki pengaruh yang cukup besar dalam keberhasilan pembelajaran mahasiswa milenial di Indonesia karena dapat dilihat bahwa generasi milenial sudah mulai jenuh dan bosan dengan pembelajaran tatap muka tanpa jeda. Penggunaan E-learning berpengaruh terhadap motivasi belajar mahasiswa karena dalam sistem ini mahasiswa dituntut untuk lebih kreatif dan mandiri mencari informasi dari berbagai sumber kapanpun dan dimanapun.Dengan demikian, pembelajaran menggunakan E-learning dapat terapkan dan dimaksimalkan karena terbukti meningkatkan motivasi belajar mahasiswa milenial PTKIN dari berbagai provinsi di Indonesia.

Kata Kunci: E-learning, Motivasi Belajar, Mahasiswa PTKIN 


\section{PENDAHULUAN}

Pesatnya perkembangan Teknologi Informasi dan Komunikasi (TIK) pada saat ini menuntut adanya perubahan proses belajar mengajar. Mulai dari jenjang SD sampai Perguruan Tinggi sekarang sistem pembelajarannya menggunakan teknologi informasi. Jika tidak menyelaraskan dengan perkembangan zaman, maka akan tertinggal dengan kemajuan teknologi yang akan terus berkembang. Generasi muda saat ini punterkenal dengan sebutan generasi milenial yang karakteristiknya pasti berbeda dengan generasi terdahulu Purnomo et al. (2016) .

Menurut Gideon (2018) Generasi milenial juga sering disebut dengan istilah "kids zaman now" yang gaya hidupnya selalu bergantung pada gadget. Karena, mereka merasa bahwa gadget ataupun teknologi membuat mereka dapat mengakses berbagai informasi penting setiap harinya. Seharusnya dengan adanya perkembangan teknologi tersebut dapat dimanfaatkan dengan baik untuk pendidikan, terutama kepada mahasiswa. Karena di universitas luar negeri sudah diterapkan metode pembelajaran E-learning di mana mahasiswa tidak perlu tatap muka dengan dosennya, kecuali ada project yang harus diselesaikan. E-learning itu sendiri merupakan kegiatan atau media pembelajaran berbasis web dan dapat dengan mudah diakses melalui internet dengan kebebasan waktu dan tempat. Hal tersebut membuat mahasiswa lebih enjoy, aktif dan kreatif dalam mencari informasi terbaru dalam proses pembelajaran Sianturi and Lisum (2018).

Pembelajaran dengan sistem teknologi dan informasi yang baru menimbulkan pengaruh yang besar terhadap dunia pendidikan tetapi motivasi belajar mereka malah menurun drastis, karena banyak yang menyalahgunakan penggunaan internet yaitu mereka bukan untuk mencari informasi yang berkaitan dengan ilmu pengetahuan tetapi dengan hal yang tidak ada hubungannya dengan ilmu pengetahuan.Hal tersebut harus disadari bersama, supaya tujuan dari Pendidikan Nasional tetap konsisten dengan mengikuti zaman milenial saat ini Barni (2019). Terutama untuk Perguruan Tinggi, seharusnya dosen lebih peka untuk penggunaan $e$ learning sebagai sistem pendukung dalam sistem pembelajaran mereka.Jika itu sudah diterapkan dengan baik, pastinya mahasiswa juga dapat saling berbagi informasi dan mengakses bahan-bahan ajar setiap saat mereka butuhkan. Karena, dari tahun ke tahun pastinya penerimaan mahasiswa baru akan terus bertambah dan hal tersebut akan berpengaruh kepada sarana dan prasarana yang dibutuhkan dalam proses pembelajaran yang akan menimbulkan akibat kepada motivasi belajar bagi mahasiswa.

Motivasi belajar merupakan hal yang penting untuk menunjang keberhasilan mahasiswa.Motivasi belajar pun bersifat pribadi dan berasal dari dalam diri individu itu sendiri.Karena motivasi yang besar mampu menjadikan seorang yang tadinya tidak mampu menjadi mampu, orang yang tidak bisa menjadi bisa.Tujuan dari penggunaan ataupun penerapan e-learning dalam perkuliahan yaitu agar meningkatkan motivasi belajar mahasiswa yang akan memberikan efek pada prestasi belajar mereka Ibrahim and Suardiman (2014). Penggunaan E-learning merupakan salah satu pendorong motivasi belajar mahasiswa. Oleh karena itu, dalam penelitian ini akan dilakukan evaluasi "pengaruh penggunaan E-learning terhadap motivasi belajar mahasiswa di Indonesia". Hasil dari penelitian ini dapat dijadikan acuan kedepannya untuk dosen maupun perguruan tinggi agar lebih memperhatikan faktor yang mempengaruhi motivasi belajar mahasiswa yang akan berimplikasi pada hasil belajar mahasiswa.

\section{METODE}

Berdasarkan landasan teori dan penelitian terdahulu, maka penelitian ini bertujuan untuk menganalisis pengaruh antara variabel independen berupa e-learning dengan variabel dependen yakni motivasi belajar mahasiswa.

[Figure 1 about here.]

Menurut Darliah (2016) Penelitian yang dilakukan adalah penelitian Ex Post Facto yang artinya bahwa penelitian tentang variabel tersebut sudah terjadi sebelum penelitian dilaksanakan.Penelitian ini juga bertujuan untuk menggambarkan keadaan lapangan dengan menggunakan pendekatan kuantitatif.Penelitian ini digunakan untuk meneliti pada populasi atau sampel tertentu, dan teknik pengambilan sampel dilakukan secara random, pengumpulan data, serta menggunakan instrument penelitian Sugiyono (2017) .

Dalam penelitian ini populasinya adalah Mahasiswa PTKIN dari berbagai provinsi di Indonesia. Sedangkan, sampel yang digunakan dalam studi penelitian ini yaitu sebanyak 103 mahasiswa dari berbagai provinsi di Indonesia dengan menggunakan kuesioner atau angket.Serta teknik untuk mendapatkan data yang dibutuhkan dalam penelitian ini adalah data primer. Pengumpulan data primer dilakukan dengan cara membagikan kuesioner secara online kepada mahasiswa PTKIN dari berbagai provinsi di Indonesia. Data tersebut kemudian dianalisis secara deskriptif dan diolah dengan menggunakan analisis kuantitatif. Hernawati and Aji (2016)

\section{HASIL DAN PEMBAHASAN}

Pada Tabel 1 data yang disajikan mengenai karakteristik responden seperti jenis kelamin, usia serta provinsi dari responden.

\section{[Table 1 about here.]}

Berdasarkan Tabel 1, dapat diketahui bahwa responden dalam studi ini 103 responden didominasi oleh perempuan yang terdiri dari $65,0 \%$ atau sebanyak 67 responden dan sisanya $35,0 \%$ laki-laki yaitu sebanyak 36 responden.Hal ini menunjukkan bahwa responden yang digunakan dalam penelitian ini mayoritas perempuan. Menurut usia, responden dalam studi ini didominasi oleh responden berusia 18-20 tahun, sebanyak 
71 mahasiswa atau $69,0 \%$, responden, sisanya berusia $21-23$ sebanyak 32 mahasiswa atau 31,0\% responden. Sedangkan, Karakteristik demografi responden di dominasi oleh provinsi Jawa Tengah sebanyak 71 orang atau $68,8 \%$, sisanya berasal dari Aceh sebanyak 1 orang atau 1,0\%, Banten sebanyak 2 orang atau 2,0\%,Bengkulu sebanyak 3 orang atau 2,9\%, D.I Yogyakarta sebanyak 1 orang atau 1,0\%, DKI Jakarta sebanyak 12 orang atau $11,8 \%$, Jawa Barat sebanyak 7 orang atau 6,9\%, Jawa Timur sebanyak 2 orang atau 2,0\%, Kalimantan Barat sebanyak 1 orang atau 1,0\% dan Lampung sebanyak 3 orang atau $2,9 \%$.

Dalam penelitian, penulis menggunakan alat pengumpulan data berupa angket kuesioner dengan menggunakan skala ordinal atau sering disebut skala likert sebagai alat ukur jawaban dari responden. Kuesioner tersebut terbagi menjadi dua bagian, yaitu: Bagian pertama berisi tentang identitas responden yang meliputi nama, jenis kelamin, usia dan provinsi. Lalu, bagian kedua berisi tentang pertanyaan-pertanyaan untuk diisi oleh responden.Kemudian kuesioner tersebut diatur dengan pilihan jawaban yang disesuaikan pada skala likert 5 poin. Seperti, poin 1 pada skala likert yang digunakan yaitu sangat tidak setuju sedangkan untuk poin 5 pada skala likert yaitu sangat setuju. Karwati (2014) Penelitian ini juga menggunakan uji validitas dan reliabilitas yaitu untuk menguji instrumen penelitian.Uji validitas digunakan untuk mengukur seberapa valid tidaknya suatu kuesioner sedangkan uji reliabilitas yaitu untuk menghitung seberapa reliabelnya suatu kuesioner.Hasil uji validitas dan reliabilitas disajikan pada Tabel 2 danTabel 3 .

\section{[Table 2 about here.]}

Tabel 2 menunjukkan pengujian KMO dan Bartlett Sphericity, yang dapat dilihat bahwa nilai uji KMO sama dengan 0,887 yang berarti nilai tersebut lebih baik karena melebihi taraf siginifikan 0,05. Sedangkan untuk nilai uji Bartlett Sphericity yaitu 0,000 yang berarti hasil tes tersebut memperoleh hasil yang signifikan karena kurang dari taraf signifikan 0,05. Sehingga dapat dikatakan seluruh pertanyaan yang digunakan dalam penelitian ini valid dan dapat digunakan pada keseluruhan model pengujian.

\section{[Table 3 about here.]}

Tabel 3 menunjukkan nilai uji reliabilitas yaitu untuk mengukur kehandalan suatu kuesioner yang merupakan indikator dari variabel penelitian.Untuk mengukur reliabilitas ini menggunakan uji statistik yaitu melihat nilai cronbach alpha.Suatu variabel dikatakan reliabel jika nilai cronbach alpha lebih dari 0,70 dan dapat diketahui bahwa nilai dari cronbach alpha penelitian ini untuk variabel penggunaan E-learning yaitu 0,892 serta variabel motivasi belajar yaitu 0,907 yang dapat diartikan bahwa pengukuran masing-masing variabel dari kuisioner penelitian inidinyatakan reliable, sehingga semua butir pertanyaan dapat dipercaya dan dapat digunakan untuk penelitian sebelumnya.
Uji yang akan digunakan ini merupakan uji regresi untuk membuktikan hipotesis dalam studi ini. Uji ini bertujuan untuk menguji dan mengukur efek variabel independen pada variabel dependen.Uji ini juga menggunakan bantuan program SPSS.

\section{[Table 4 about here.]}

BerdasarkanTabel 4 , hasil pengujian hipotesisdapat dilihat bahwa nilai $\mathrm{R}$ sebesar 0,686 , nilai $\mathrm{R}$ Square adalah 0,470 , Adjusted R Square nilai 0,465. hasil tersebut menjelaskan bahwa variasi variabel independen mampu menjelaskan variabel dependen sebesar $46,5 \%$, sedangkan sisanya sebesar $53,5 \%$ dijelaskan variasi variabel lain yang tidak diteliti oleh peneliti, misalnya kualitas informasi, penerapan konten serta keterampilan dari dosen maupun pengajar lainnya.

Uji yang digunakan selanjutnya yaitu uji T-test, uji ini digunakan untuk melihat signifikansi pengaruh variabel independen terhadap variabel dependen.Ternyata dalam penelitian ini mengetahui bahwa penggunan e-learning memiliki efek positif dan signifikan pada motivasi belajar mahasiswa.Hal ini dapat dilihat dari hasil uji regresi 0,470 , dengan nilai T dihitung pada 9,463 dan nilai signifikansi 0,000. Nilai SIG yang lebih kecil dari 0,05 itu menandakan bahwa terdapat pengaruh yang signifikan antara penggunaan E-learningterhadap motivasi belajar mahasiswa, hal tersebut juga menyatakan jika penggunaan E-learningmeningkat, maka otomatis motivasi belajar mahasiswa juga semakin meningkat.

Sedangkan uji F-test dilakukan untuk mengatur seberapa jauh variabel independen mempengaruhi variabel dependen.Pada table di atas menunjukkan bahwa uji F-test memperoleh hasil 89,543 dengan nilai signifikan 0,000. Hasil ini menunjukkan bahwa semakin tinggi penggunaan e-learning dapat meningkatkan motivasi belajar mahasiswa.Penelitian ini juga sependapat dengan Azhar Arsyad (2011) yang mengatakan bahwa proses pembelajaran itu dapat membangkitkan keinginan, motivasi serta rangsangan untuk proses pembelajaran.

\section{KESIMPULAN}

Berdasarkan hasil penelitian yang telah dilakukan melalui tahap pengumpulan data, pengolahan data dan analisis data mengenai pengaruh penggunaan e-learning terhadap motivasi belajar mahasiswa maka dapat ditarik kesimpulan sebagai berikut: Penggunaan E-learning dalam pembelajaran memiliki pengaruh yang cukup besar dalam keberhasilan pembelajaran mahasiswa diIndonesia karena dapat dilihat bahwa generasi milenial sudah mulai jenuh dan bosan dengan pembelajaran tatap muka tanpa jeda. Penggunaan E-learning berpengaruh terhadap motivasi belajar mahasiswa karena dalam sistem ini mahasiswa dituntut untuk lebih kreatif dan mandiri mencari informasi dari berbagai sumber kapanpun dan dimanapun. Adapun pengaruh positif dan signifikan terhadap motivasi belajar mahasiswa PTKIN di Indonesia dengan $\mathrm{t}_{\text {hitung }}$ 
9,463dengan taraf signifikansinya $\leq$ 0,05.Pengaruh tersebut berada dalam kategori yang tinggi.Mahasiswa menunjukkan kesediaan pembelajaran menggunakan E-learning karena sistem dari E-learning ini sangat diperlukan untuk mengantisipasi perkembangan jaman terutama dengan adanya generasi milenial dan dukungan teknologi informasi yang menuju ke era yang lebih baik lagi.

\section{REFERENCES}

Barni, M. (2019). Tantangan Pendidik Di Era Millenial. TRANSFORMATIF 3, 99116. doi: $10.23971 /$ tf.v3i1.1251.

Darliah, L. (2016). Pengaruh kualitas informasi dan penggunaan e-learning terhadap prestasi belajar dengan motivasi belajar sebagai variabel intervening (studi pada mahasiswa pendidikan ekonomi FE UNY angkatan 2012-2013 mata kuliah statistika II dan aplikasi computer II). https://eprints.uny.ac.id/38961/.

Gideon, S. (2018). Peran media bimbingan belajar online "ruang guru" dalam pembelajaran IPA bagi siswa SMP dan SMA masa kini: Sebuah pengantar. Jurnal Dinamika Pendidikan 11, 167-182. doi: https://doi.org/10.33541/jdp.v11i2.813.

Hernawati, E. and Aji, P. (2016). Perancangan dan Penerapan Konten e-Learning melalui Learning Management System dalam Meningkatkan Motivasi Belajar Studi Kasus pada Mata Kuliah Pemrograman Basis Data. Journal of Information Systems Engineering and Business Intelligence 2, 23-23. doi: 10.20473/jisebi. 2.1.23-32.

Ibrahim, D. S. and Suardiman, S. P. (2014). Pengaruh Penggunaan E-Learning Terhadap Motivasi Dan Prestasi Belajar Matematika Siswa SD Negeri Tahunan Yogyakarta. Jurnal Prima Edukasia 2, 66-66. doi: 10.21831/jpe.v2i1.2645.

Karwati, E. (2014). Pengaruh Pembelajaran Elektronik (E-Learning) terhadap Mutu Belajar Mahasiswa. Jurnal Penelitian Komunikasi 17, 41-54. doi: 10.20422/jpk. v17i1.5.

\section{UCAPAN TERIMA KASIH}

Tak lupa kami ucapkan terima kasih kepada rekan-rekan di IAIN Salatiga yang selalu memberikan dukungan sehingga kami dapat menyelesaikan artikel ini.

Purnomo, A., Ratnawati, N., and Aristin, N. F. (2016). Pengembangan Pembelajaran Blended Learning Pada Generasi Z. Jurnal Teori dan Praksis Pembelajaran IPS 1, 70-76. doi: 10.17977/um022v1i12016p070.

Sianturi, S. R. and Lisum, K. (2018). Peningkatan motivasi belajar melalui evaluasi e-learning pada institusi keperawatan di Jakarta dan Depok. Jurnal Pendidikan Keperawatan Indonesia 4, 122-130. doi: https://doi.org/10.17509/jpki. v4i2.11563.

Sugiyono (2017). Metode Penelitian Kuantitaif, Kulitatif, R\&D (Bandung: Alfabeta).

Conflict of Interest Statement: The authors declare that the research was conducted in the absence of any commercial or financial relationships that could be construed as a potential conflict of interest.

Copyright (C) 2020 Fitria, Saifudin and Zaman. This is an open-access article distributed under the terms of the Creative Commons Attribution License (CC BY). The use, distribution or reproduction in other forums is permitted, provided the original author(s) and the copyright owner(s) are credited and that the original publication in this journal is cited, in accordance with accepted academic practice. No use, distribution or reproduction is permitted which does not comply with these terms. 


\section{LIST OF TABLES}

1 Karakteristik Responden . . . . . . . . . . . . . . . . . . . . . . . . . . . . . 119

2 Hasil dari KMO dan Bartlett Sphericity . . . . . . . . . . . . . . . . . . . . . . . 120

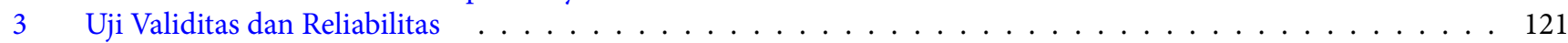

4 Koefisien determinandan R Square dari hasil t-Test, dan F-Test . . . . . . . . . . . . . . . . . . . . . . . 122 
TABLE 1 | Karakteristik Responden

\begin{tabular}{ll}
\hline $\begin{array}{l}\text { Karakteristik } \\
\text { Jenis Kelamin } \\
\text { Laki-laki }\end{array}$ & Persentase \\
Perempuan & 35.0 \\
& 65.0 \\
Usia & \\
18 & 1.0 \\
19 & 14.6 \\
20 & 53.4 \\
21 & 26.2 \\
22 & 2.9 \\
23 & 1.9 \\
& \\
Provinsi & \\
Aceh & 1.0 \\
Banten & 2.0 \\
Bengkulu & 2.9 \\
D. I Yogyakarta & 1.0 \\
DKI Jakarta & 11.7 \\
Jawa Barat & 6.8 \\
Jawa Tengah & 68.7 \\
Jawa Timur & 2.0 \\
Kalimantan Barat & 1.0 \\
Lampung & 2.9 \\
\hline
\end{tabular}


TABLE 2 | Hasil dari KMO dan Bartlett Sphericity

Pengujian

Sample Adequacy KMO

Bartlett of Sphericity
Nilai

0.887

0.000 
TABLE 3 | Uji Validitas dan Reliabilitas

Indikator Item Skor

E-learning (CR=0.892)

Dosen menggunakan E-learning sebagai media pembelajaran

Mahasiswa belum terbiasa menggunakan E-learning dalam pembelajaran

0.903

Dosen memberikan file melalui media E-learning

0.883

Materi yang diberikan melalui media E-learning lebih mudah dipahami

0.886

Materi dapat diunduh kapanpun dan dimanapun melalui E-learning

0.883

Dosen selalu memberikan quiz lewat media E-learning

0.880

Mahasiswa mengumpulkan jawaban quiz melalui E-learning

0.878

Dosen selalu memberikan tugas melalui media E-learning

0.877

Mahasiswa mengumpulkan jawaban tugas melalui E-learning

0.877

Tugas yang menggunakan media E-learning dapat dikumpulkan tepat waktu

0.885

Mahasiswa pernah memanfaatkan forum diskusi dalam E-learning

0.895

0.893

Mahasiswa pernah memanfaatkan forum chat untuk berdiskusi mengenai materi mata kuliah

0.884

Dosen dan mahasiswa mengetahui statistik perkembangan nilai melalui E-learning

0.883

Motivasi Belajar (CR=0.907)

Mahasiswa mengerjakan tugas dengan baik meskipun tugas yang diberikan dosen cukup banyak 0.905

Mahasiswa mengerjakan tugas dengan baik agar memperoleh hasil yang maksimal 0.896

Tugas kuliah dari dosen berusaha dikerjakan meskipun sulit

0.895

Mahasiswa berusaha mempelajari dan memahami materi kuliah

0.898

Mahasiswa menanyakan materi kuliah yang belum jelas kepada dosen 0.892

Mahasiswa merasa tertantang untuk mempelajari materi yang sulit 0.903

Soal-soal yang ada dimodul mata kuliah selalu dikerjakan tanpa disuruh oleh dosen 0.894

Mahasiswa mengerjakan tugas dosen secara mandiri 0.892

Mahasiswa mengerjakan quiz dari dosen sendiri, tidak terpengaruh oleh jawaban teman 0.890 
TABLE 4 | Koefisien determinandan R Square dari hasil t-Test, dan F-Test

\begin{tabular}{ll}
\hline & PE to MBM \\
Determinant Coefficient and Adjusted R & \\
R & 0.686 \\
R2 & 0.470 \\
Adjusted R Square & 0.465 \\
Standardized Coefficient Beta & \\
T & 9.463 \\
Sig. & 0.000 \\
Result of F test & \\
F & 89.543 \\
Sig. & 0.000 \\
\hline
\end{tabular}




\section{LIST OF FIGURES}

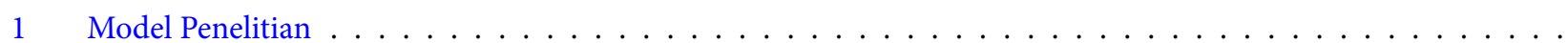




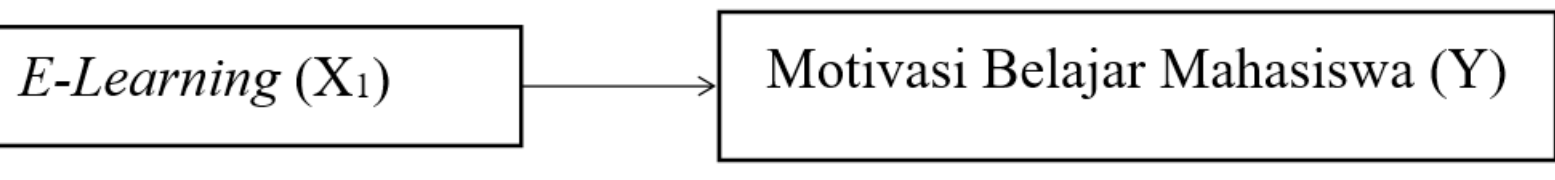

FIGURE 1 | Model Penelitian 